\title{
In vitro tests of dense hydroxyapatite materials
}

\author{
Agnieszka Sobczak, Anna Kida, Zygmunt Kowalski, Zbigniew Wzorek \\ Cracow University of Technology, Institute of Inorganic Chemistry and Technology, ul. Warszawska 24, 31-155 Kraków, \\ Poland, e-mail: asobczak@chemia.pk.edu.pl
}

\begin{abstract}
The paper presents the results of the calcining process of deproteinised and defatted bone pulp called bone sludge. The calcining process was performed in two stages. The first step of the calcining process was realized at the temperature of $600^{\circ} \mathrm{C}$ in a rotary kiln. In the second stage the obtained bone ashes were calcined at five different temperatures from $650^{\circ} \mathrm{C}$ to $950^{\circ} \mathrm{C}$ for 2 hours in a chamber kiln and in air atmosphere. The products of the calcining process were characterized by the XRD method. Calcium content was determined by titration whereas the contents of total phosphorus and acid-soluble phosphorus - by the spectrophotometric method. The X-ray analysis confirmed that hydroxyapatite is the main component of the calcining products. Calcium and phosphorus contents were kept at the level of $40 \%$ and $17.5 \%$, respectively, which corresponded to the $\mathrm{Ca} / \mathrm{P}$ ratio of not stechiometric hydroxyapatite. In vitro studies, in the simulated body fluid, Ringer liquid and distilled water were realised. The measurements of $\mathrm{pH}$ value of SBF and Ringer fluid were realized. Additionally electrical conductivity as well as $\mathrm{pH}$ for distilled water where conducted. The goal of these tests was to evaluate chemical durability of dense hydroxyapatite materials.
\end{abstract}

Keywords: hydroxyapatite, dense materials, in vitro tests, incubation.

\section{INTRODUCTION}

Different kinds of materials are applied in repair and reconstructive medicine, of special importance being hydroxyapatite HA biomaterials, which substituted the destroyed or damaged bone tissues. It is possible due to particular properties of HAp, i.e.: chemical and phase composition, microstructure, high biocompatibility, bioactivity and bioconductivity ${ }^{1}$. The hydroxyapatite material adapts in a human body and it does not demonstrate toxic properties. HAp ceramic does not induce sharp or chronic pathological states, however it is active in the regeneration process of tissue. High biocompatibility resulted from a chemical similarity of an implant to natural bone apatite ${ }^{2-5}$. The surface of HAp creates optimal conditions for the accretion of a new bone tissue. A bioactive material creates an environment compatible with osteogenesis (bone growth), with the mineralizing interface developing as a natural bonding junction between living and non-living materials. The connection between the bone and implant resulted from a biological and physicochemical process. Osteogeneration consists in direct, functional and structural adhesion of an implant to the bone surface $^{2-5}$.

Dense hydroxyapatite implants have an application as surgical and stomatological implants. They are used as bone eye ground and in laryngology as middle ear implants. Moreover, dense HAp materials could be applied as PD (Percutaneous Device) implants, which are part of equipment, for example for dialysis. In hard tissue engineering, properties like bioresorption and biocompatibility are made use of, and hydroxyapatite has an application as a scaffold ${ }^{2}$.

\section{EXPERIMENTAL PROCEDURES}

\section{Preparation of hydroxyapatite}

The preparation method was developed in the Institute of Inorganic Chemistry and Technology at the Cracow University of Technology. Bone sludge was applied as a raw material that was formed as a by-product in the deproteinisation process of pork bones, the main product of which was a protein hydrolisate.

Hydroxyapatite was obtained in the calcining process in two stages. In the first stage the material was calcined at the temperature of $600^{\circ} \mathrm{C}$ in a rotary kiln with gaseous heating. In the next stage the unified material (sieve fraction below $0.15 \mathrm{~mm}$ ) was calcined at the temperatures of $650^{\circ} \mathrm{C}, 700^{\circ} \mathrm{C}$, $800^{\circ} \mathrm{C}, 900^{\circ} \mathrm{C}$ and $950^{\circ} \mathrm{C}$, keeping the material at the maximum temperature for 2.0 hours in a chamber kiln with electric heating in air atmosphere. Two series of measurement were realised simultaneously.

The phase composition determined with the X-Ray method on Philips X'Pert diffractometer equipped with a graphite monochromator showed that hydroxyapatite was the only crystalline phase observed in the calcining products. However, the crystallisation degree was dependent on the calcining temperature and increased with the temperature of the process.

Table 1. Losses of weight at the time of the calcining process at different temperatures

\begin{tabular}{|l|c|c|c|c|c|}
\hline \multirow{2}{*}{} & \multicolumn{5}{|c|}{ Loss of weight [\%] of Hap obtained at } \\
\cline { 2 - 6 } & $650^{\circ} \mathrm{C}$ & $700^{\circ} \mathrm{C}$ & $800^{\circ} \mathrm{C}$ & $900^{\circ} \mathrm{C}$ & $950^{\circ} \mathrm{C}$ \\
\hline Series I & 16.7 & 15.8 & 19.5 & 17.5 & 18.4 \\
\hline Series II & 17.4 & 16.4 & 18.4 & 20.0 & 18.0 \\
\hline
\end{tabular}

The general tendency was an increase of weight losses with the calcining temperature. It confirmed that all the organic compounds were removed from the samples. The decomposition of carbonate groups that are present in natural bone was observed at $800^{\circ} \mathrm{C}$.

The content of total phosphorus, phosphorus soluble in $0.4 \%$ hydrochloric acid and $2.0 \%$ citric acid were defined by the spectrophotometric method according to the PN-88/C87015 with Marcel Media spectrophotometer. The determination of total phosphorus content was done after former mineralization of the sample in a mixture of concentrated hydrochloric and nitric acids. Calcium was determined by the titration method according to the PN-R-64750: 1993. 


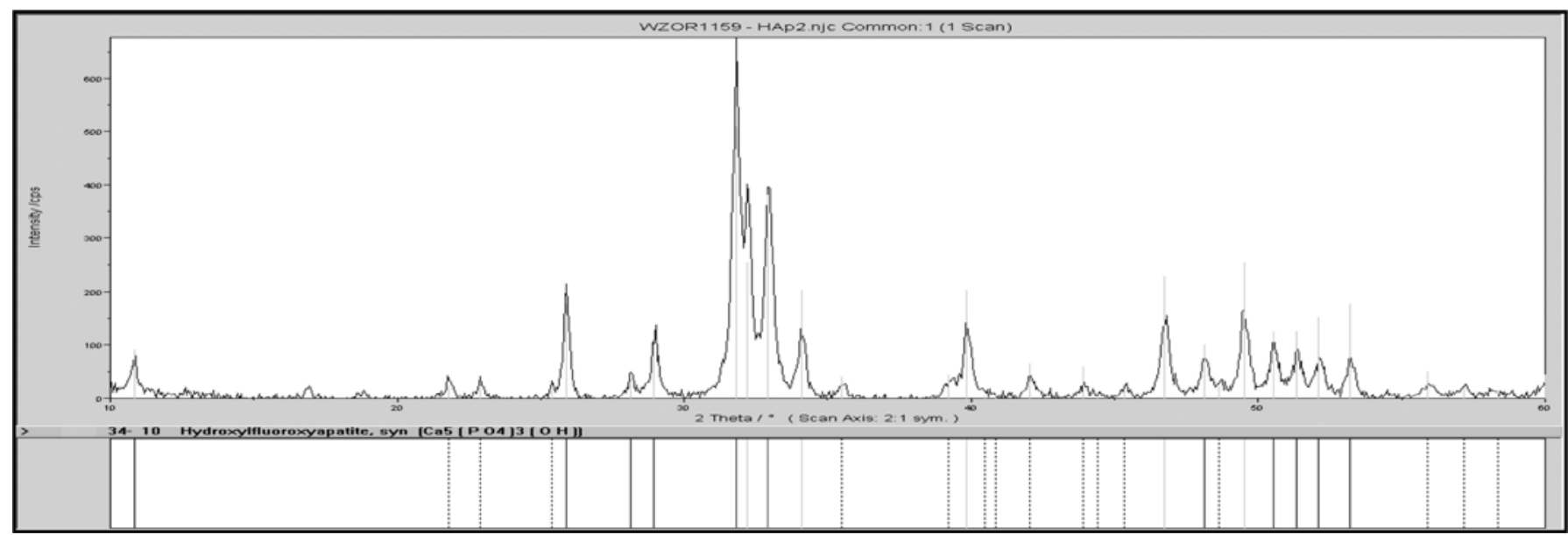

Figure 1. An X-Ray diagram of the calcining product obtained at the temperature of $650^{\circ} \mathrm{C}$

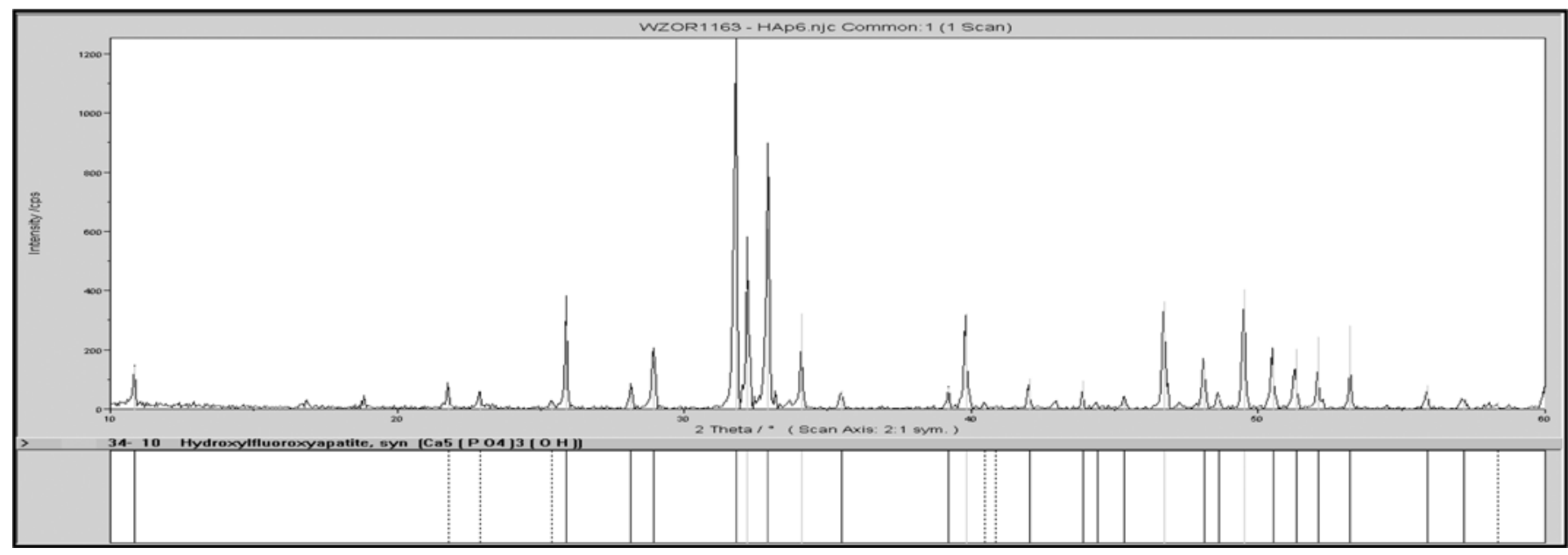

Figure 2. An X-Ray diagram of the calcining product obtained at the temperature of $950^{\circ} \mathrm{C}$

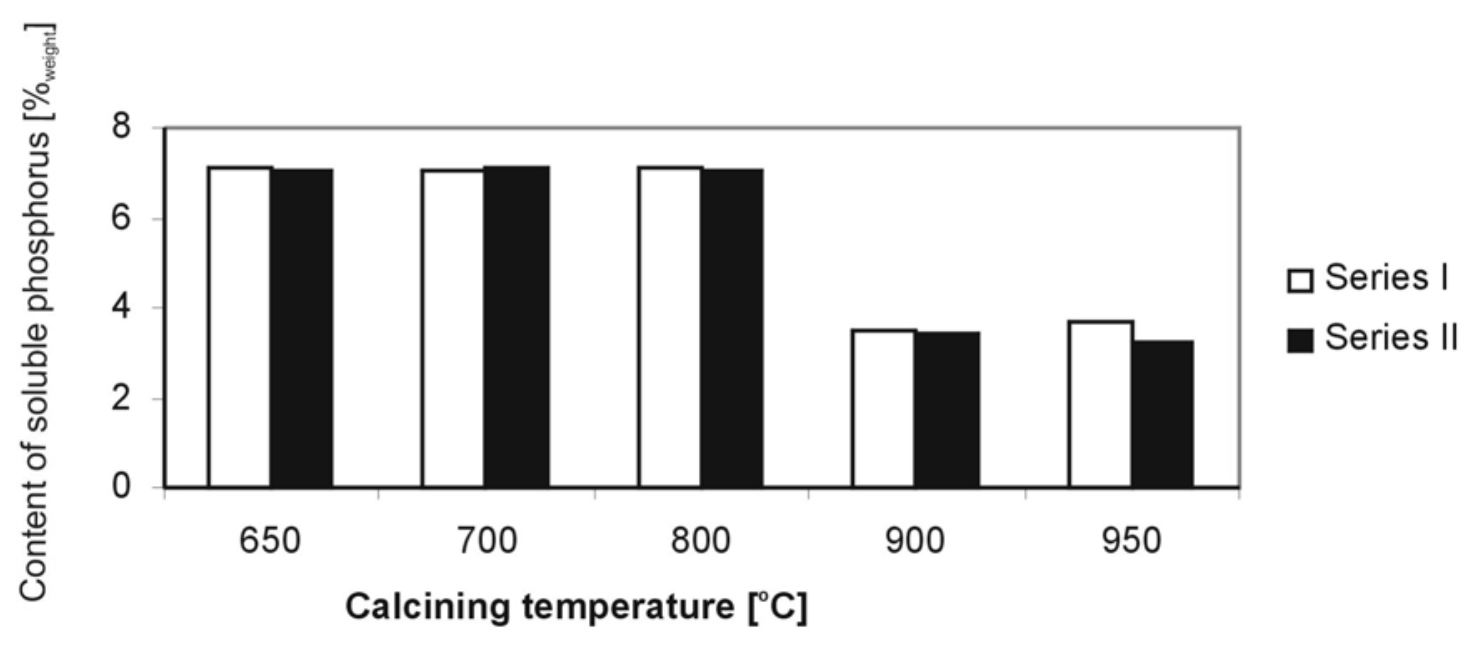

Figure 3. The content of phosphorus soluble in $0.4 \%$ hydrochloric acid in hydroxyapatite obtained at temperatures $650-950^{\circ} \mathrm{C}$

The amount of phosphorus was approximately $17.5 \%$ weight, while the quantity of calcium was in the range from $39.48 \%{ }_{\text {weight }}$ to $41.72 \%_{\text {weight. }}$. The analyses confirmed that the content of calcium and phosphorus increased with the process temperature.

The content of assimilated phosphorus was in the range from 3.25 to $7.12 \%_{\text {weight }}$. For the samples received at lowest temperatures the amount of phosphorus soluble in hydrochloric acid was higher. The content of phosphorus decreased with the calcining temperature. It could be a result of sintering of hydroxyapatite grains at the highest temperature and difficult migration inside the samples, as well as the absence of carbonate groups.

Figure 4 shows two tendencies - a decrease in the content of assimilated phosphorus up to obtaining hydroxyapatite at $800^{\circ} \mathrm{C}$, and the subsequent increase.

\section{Preparation of dense hydroxyapatite materials}

After the calcining process the samples were boiled out in distilled water for 30 minutes in order to remove a small 


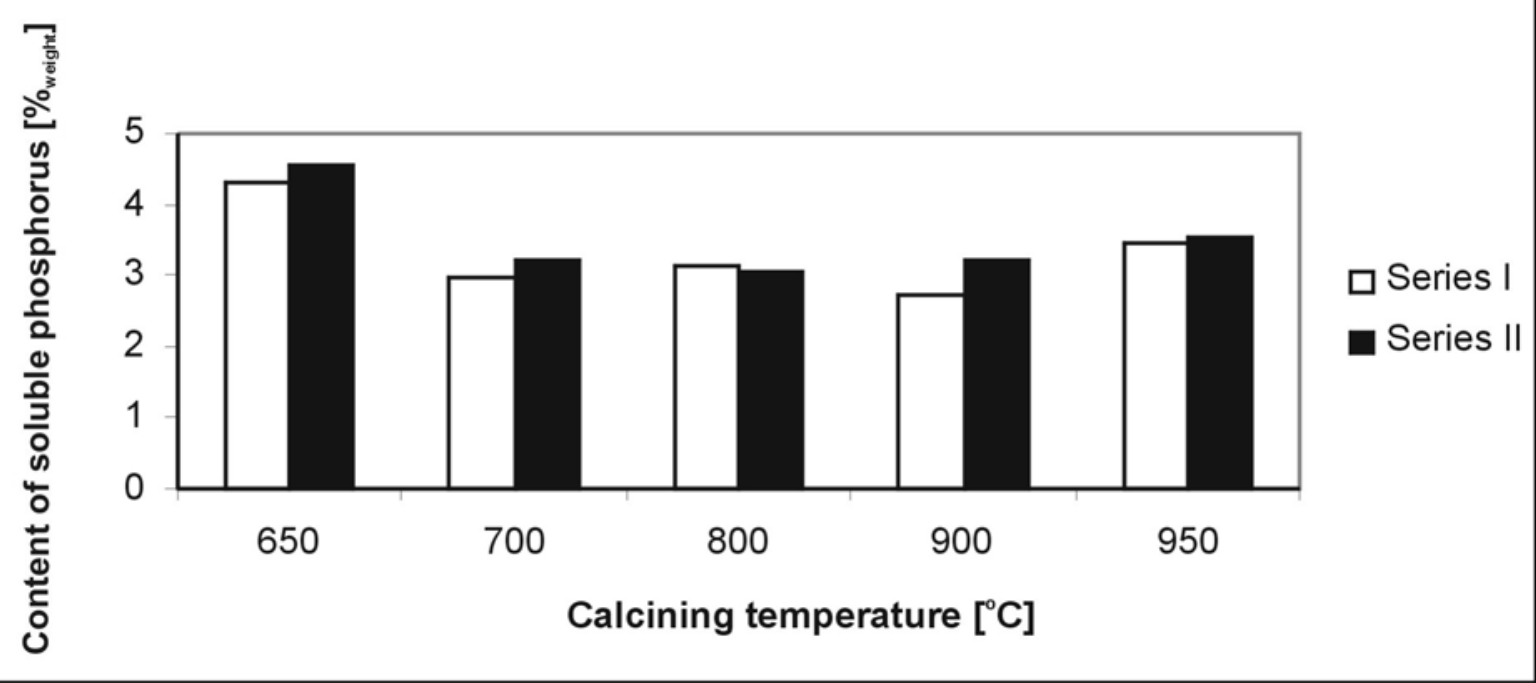

Figure 4. The content of phosphorus soluble in $2.0 \%$ citric acid in hydroxyapatite obtained at temperatures $650-950^{\circ} \mathrm{C}$

amount of calcium oxide formed during the thermal treatment. Next the samples were dried to constant mass with a weight-dryer at $105^{\circ} \mathrm{C}$. The powdered hydroxyapatite was pressed into cylindrical shape samples. Each sample had a diameter of $10 \mathrm{~mm}$ and the weight of approximately $1.1 \mathrm{~g}$. Then the cylindrical samples were sintered in a chamber kiln with electric heating in air atmosphere at $900^{\circ} \mathrm{C}$.

The in vitro researches were realised for 45 days in three types of liquid: SBF (simulated body fluid), Ringer fluid and distilled water, at the temperature of $37^{\circ} \mathrm{C}$. Five samples were put into each plastic container and $40 \mathrm{ml}$ of a proper physiological fluid were poured in. Changes of weight, $\mathrm{pH}$ and electrical conductivity of distilled water were measured. For the first seven days the measurements were made daily and then once a week. The final result was an average from five measurements. A fluid was exchanged after each measurement.

\section{In vitro tests}

Three physiological fluids were applied as an environment: Simulated Body Fluid (SBF) and Ringer fluid (solution of calcium, potassium and sodium chlorides in proper ratio), which simulated the natural human environment. Distilled water was applied in order to evaluate the degradation process of the hydroxyapatite samples. A comparison of SBF with the human plasma is shown in Table 2.

The chemical stability and biological activity were evaluated on the basis of changes in the $\mathrm{pH}$ value and electrical conductivity of distilled water. Electrical conductivity and the $\mathrm{pH}$ measurements were determined on Elmetron $\mathrm{CX}$ device equipped with a silver-silver chloride electrode and conductometer.

For all the samples an increase in the $\mathrm{pH}$ value in the initial period of incubation in a simulated body fluid was observed. Further analysed extracts showed a negligible tendency of decreasing the $\mathrm{pH}$ value with the incubation time. It concerned all the hydroxyapatite samples regardless of the

Table 2. A comparison of ions concentration and the $\mathrm{pH}$ value of SBF with the human plasma ${ }^{6}$

\begin{tabular}{|c|c|c|c|c|c|c|c|c|c|}
\hline & \multicolumn{8}{|c|}{ Ion concentration $\left[\mathrm{mmol} / \mathrm{dm}^{3}\right]$} & \multirow[b]{2}{*}{$\mathrm{pH}$} \\
\hline & $\mathrm{Na}^{+}$ & $\mathrm{K}^{+}$ & $\mathrm{Mg}^{2+}$ & $\mathrm{Ca}^{2+}$ & $\mathrm{Cl}^{-}$ & $\mathrm{HCO}_{3}{ }^{2-}$ & $\mathrm{HPO}_{4}{ }^{2-}$ & $\mathrm{SO}_{4}^{2-}$ & \\
\hline Human plasma & 142.0 & 5.0 & 1.5 & 3.5 & 103.0 & 27.0 & 1.0 & 0.5 & $7.2-7.4$ \\
\hline SBF & 142.0 & 5.0 & 1.5 & 3.5 & 147.8 & 4.2 & 1.0 & 0.5 & 7.4 \\
\hline
\end{tabular}

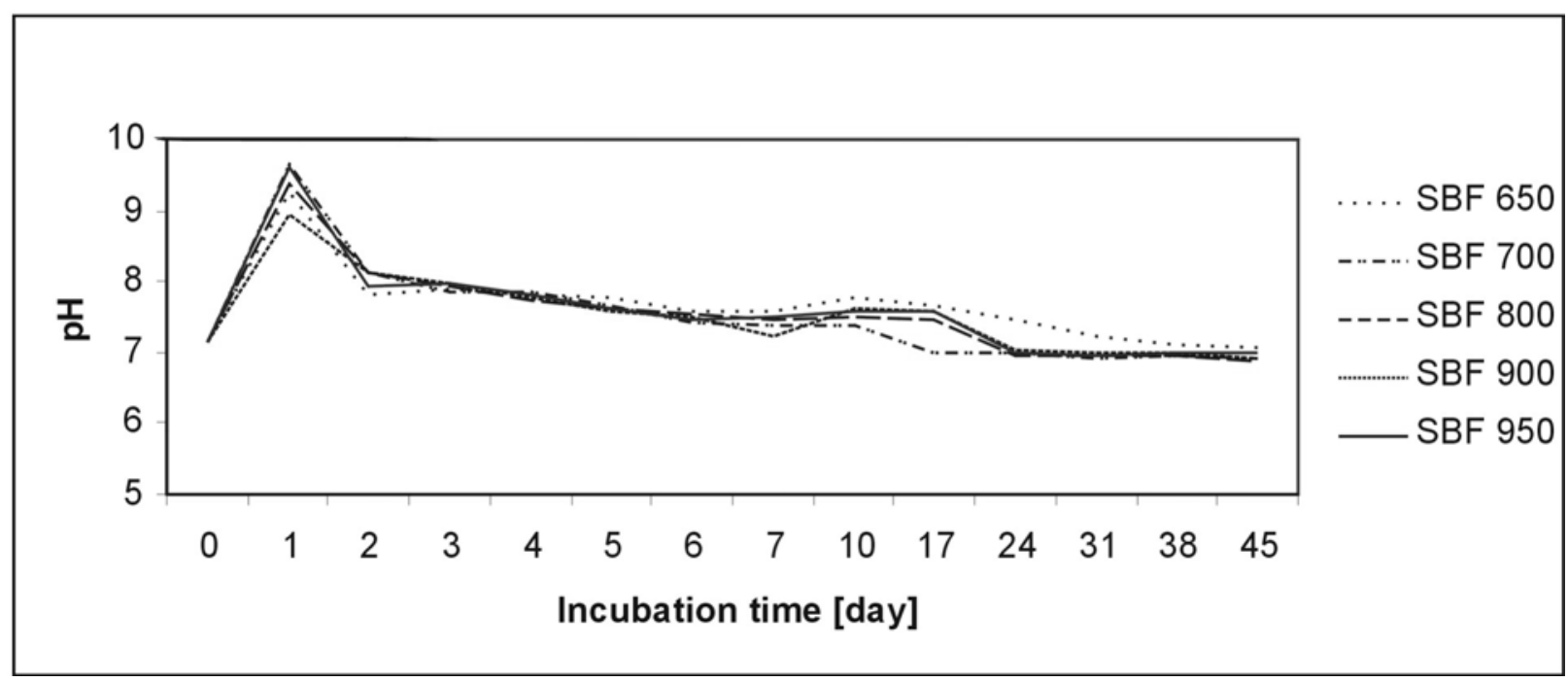

Figure 5. Changes in the $\mathrm{pH}$ value of $\mathrm{SBF}$ 


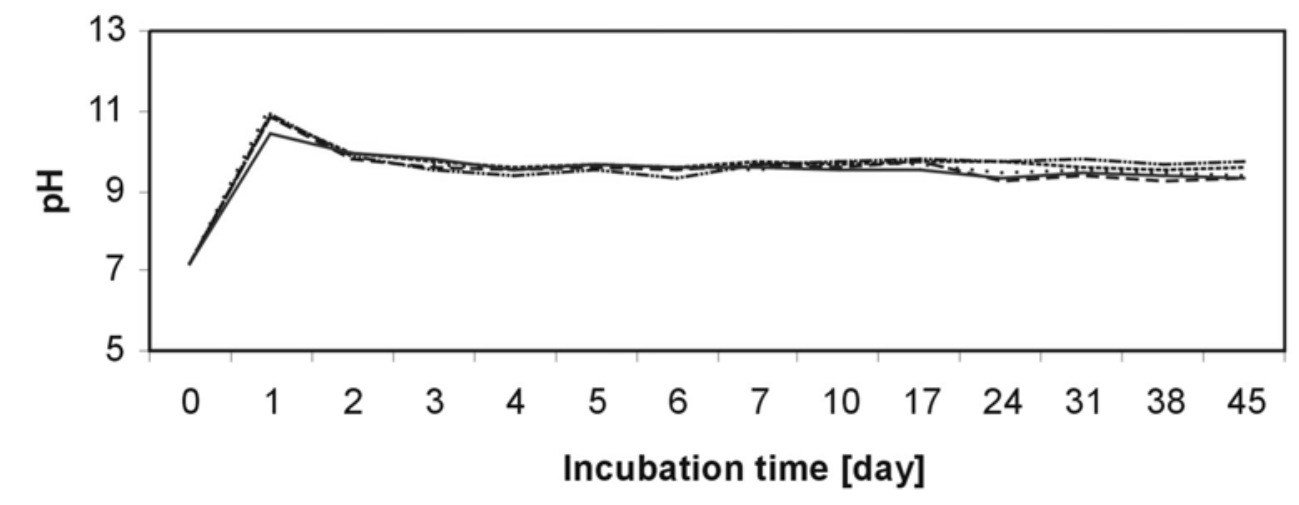

Ringer 650

Ringer 700

Ringer 800

Ringer 900

Ringer 950

\section{Incubation time [day]}

Figure 6. Changes in the $\mathrm{pH}$ value of Ringer fluid

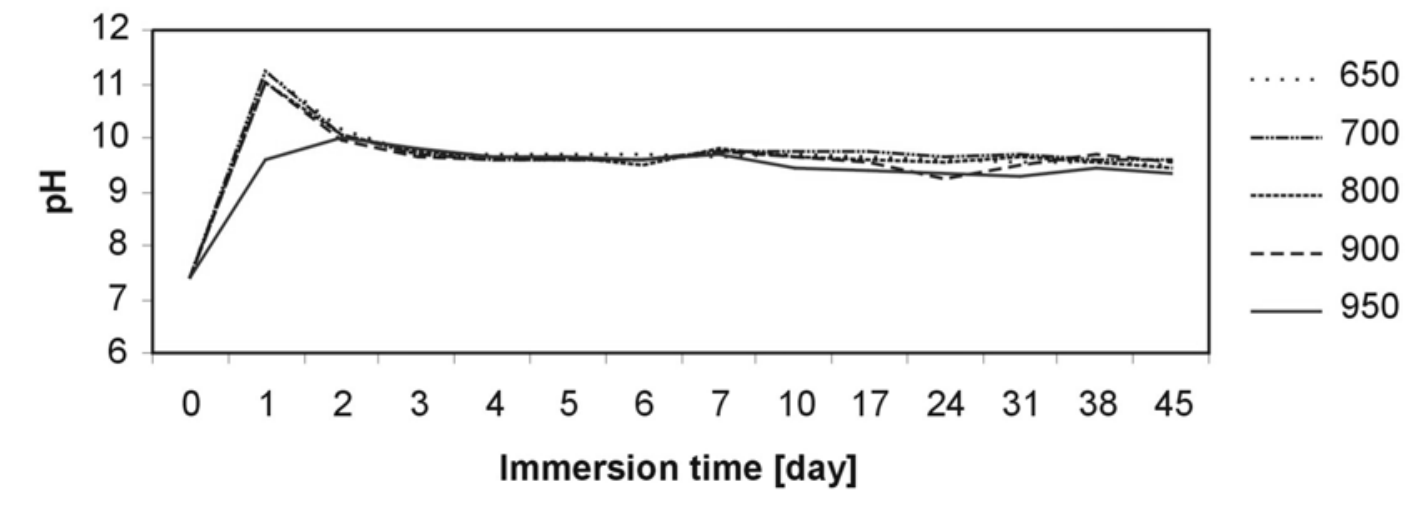

Figure 7. Changes in the $\mathrm{pH}$ value of distilled water

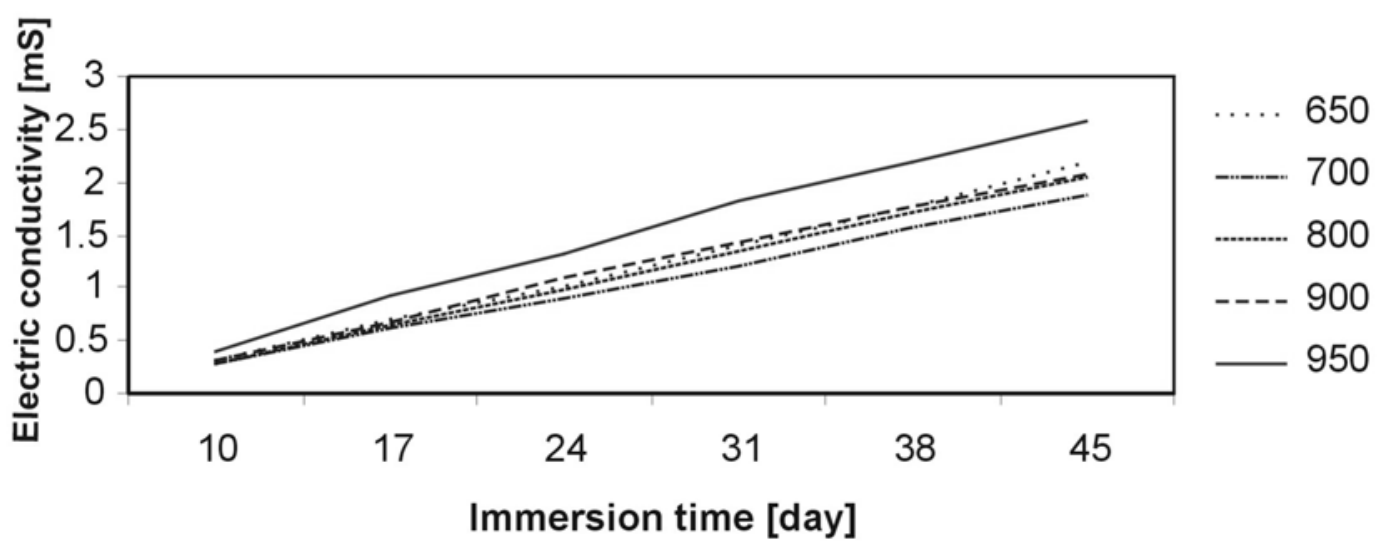

Figure 8. Changes in the electric conductivity of distilled water

calcining temperature. After a rapid growth of the $\mathrm{pH}$ of SBF up to 9.00 , a decrease up to 7.00 was observed in the final days of immersion. The sudden increase of $\mathrm{pH}$ value at the beginning of in vitro tests may be connected with free calcium oxide that was incompletly removed from samples. For the following two weeks of incubation the $\mathrm{pH}$ value was stabilized at the level of $7.50-8.00$. The highest $\mathrm{pH}$ value in comparison with pure SBF could be caused by selective desorption of calcium ions from hydroxyapatite into the solution during incubation. For all the samples immersed in a simulated body fluid changes of the $\mathrm{pH}$ value were similar, which suggested that the calcining temperature did not influence significantly the in vitro behaviour of hydroxyapatite.

Samples immersed in the Ringer fluid showed the behaviour similar to that of the samples incubated in SBF. The $\mathrm{pH}$ value increased in the first period of the in vitro test up to $\sim 11.00$. In the second period of incubation the $\mathrm{pH}$ decreased and remained at this level $\sim 9$ up to the end of the investigations. The $\mathrm{pH}$ value of pure Ringer liquid was 7.185. Also in this case the free calcium oxide is probably respon- 


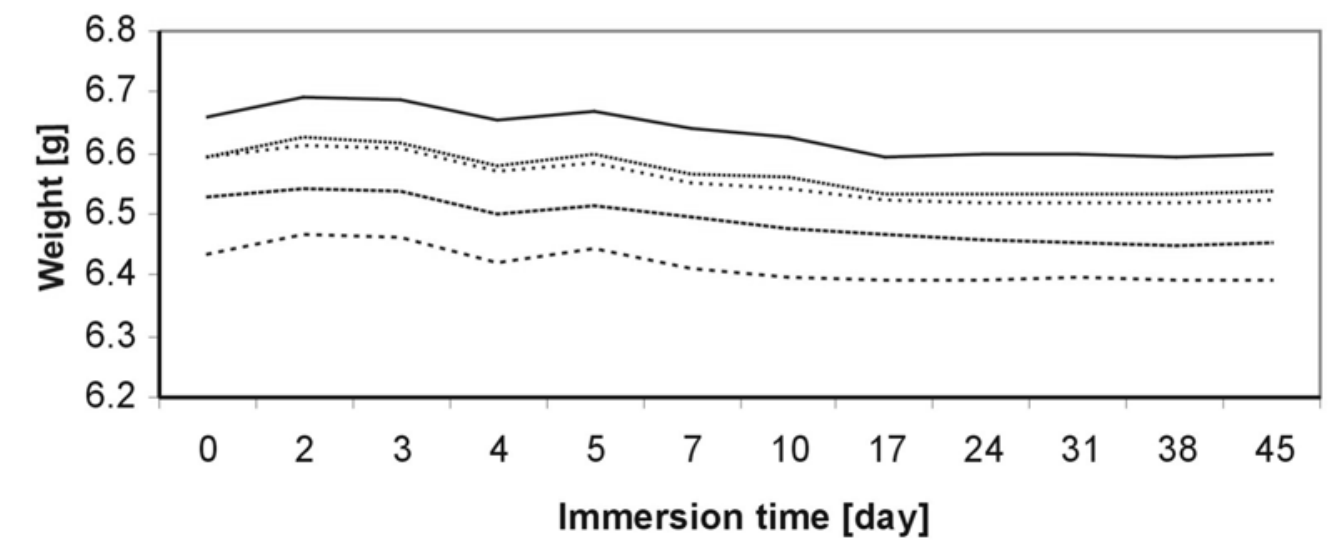

Figure 9. Changes in the mass of the samples immersed in SBF

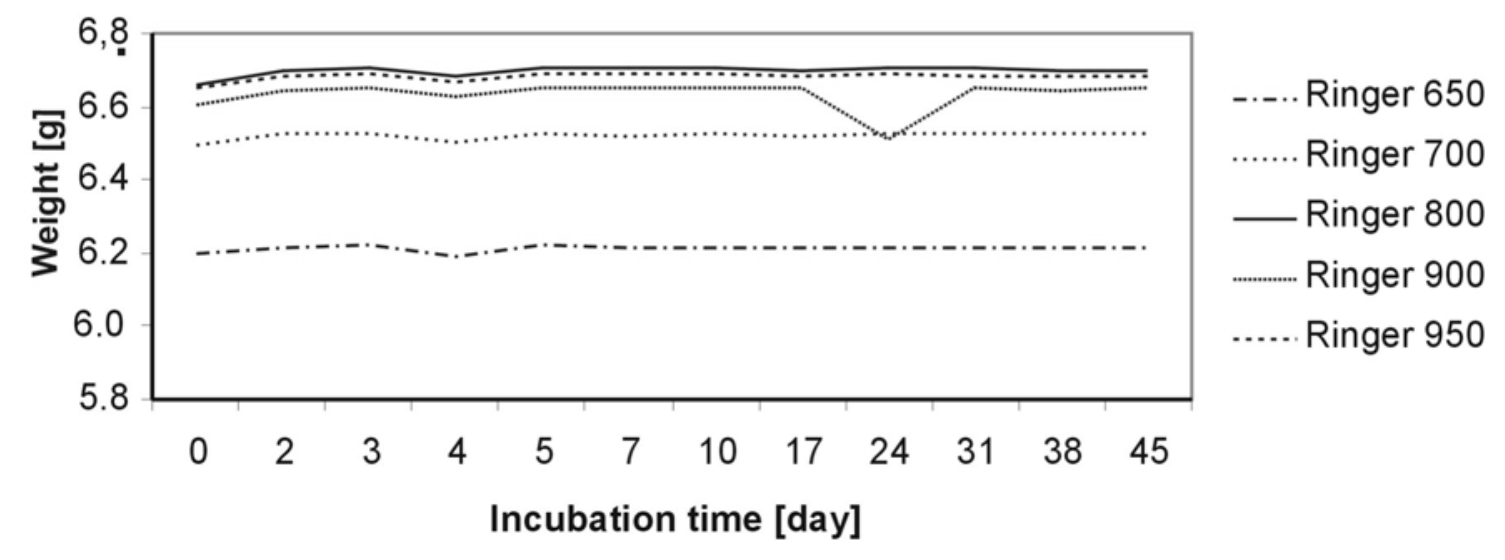

Figure 10. Changes in the mass of the samples immersed in Ringer liquid

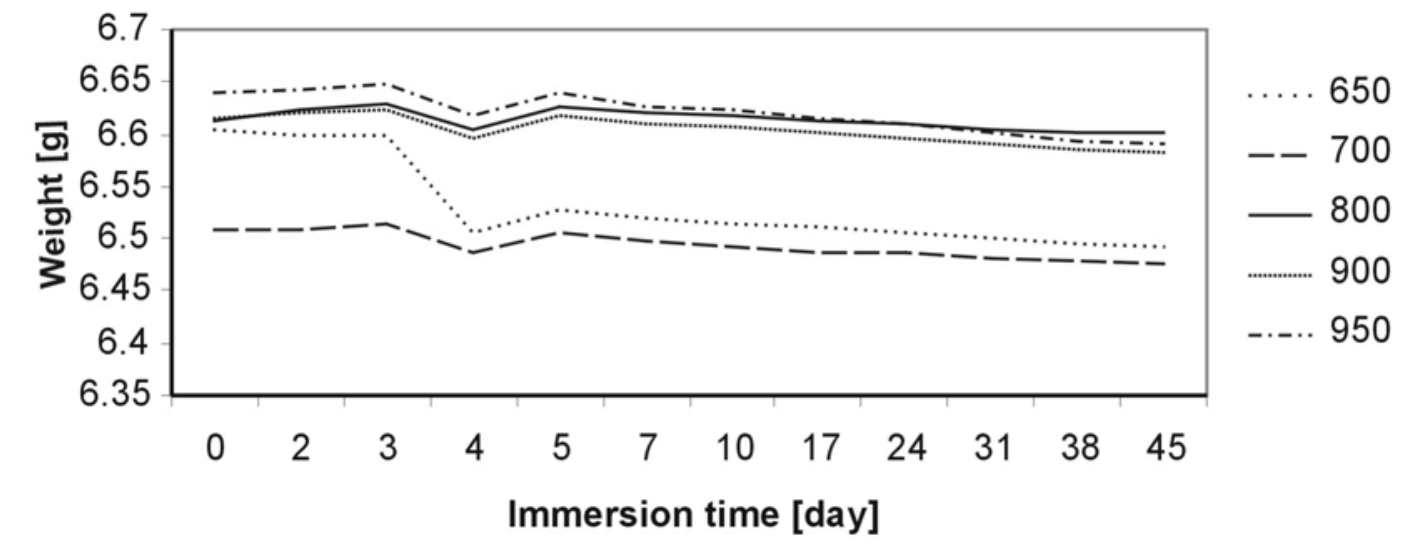

Figure 11. Changes in the mass of the samples immersed in distilled water

sible for the increase of $\mathrm{pH}$ value in the first day of immersion. On the next days the $\mathrm{pH}$ value was still at the increased level. It is caused by the calcium ions, released gradually from the hydroxyapatite surface into the solution. On the basis of $\mathrm{pH}$ measurements in physiological fluids it was confirmed that all the hydroxyapatite dense materials had bioactive properties independent of calcining temperature. Figure 7 shows changes of electric conductivity of distilled water in dependence on immersion time.
The analysed water extracts showed a similar tendency, independent of the calcining temperature of hydroxyapatite samples. At the beginning a distinct growth of the $\mathrm{pH}$ value up to approximately 11.00 was observed. An interpretation of this phenomenon was the same as in the case of SBF and Ringer, i.e. free calcium oxide. Within the next days of immersion the $\mathrm{pH}$ value stabilized at the level of above 9.00 and caused desorption of calcium ions from hydroxyapatite into the solution during the immersion. 
These measurements confirmed that all the hydroxyapatite samples were gradually degraded. The largest propensity to degradation was exhibited by hydroxyapatite samples obtained at $950^{\circ} \mathrm{C}$. An increase in electrical conductivity was characterised by linearity, it was the result of a progressive degradation process.

The changes of the mass measurements of the samples immersed in SBF indicated the loss of the masses of all hydroxyapatite materials independent of the calcining temperature. An interpretation of this effect required additional tests. It could be a result of an improper ratio between the liquid volume and a specific surface. Instead of the growth of the mass, which resulted from growing hydroxyapatite on a sample surface, we observed an inverse effect, i.e. the degradation of a hydroxyapatite surface and release of ions into the SBF solution.

The samples incubated in the Ringer fluid showed an insignificant tendency of a mass increase because of chlorides precipitation from the solution and confirmed bioactivity. All the samples exhibited a similar activity in the Ringer liquid independently of the tempearature of hydroxyapatite preparation.

The samples immersed in distilled water exhibited a tendency of a mass decrease. It was connected with the degradation process and the transition of hydroxyapatite ions into water. Fractures appeared on the sample's surface during incubation.

\section{SUMMARY}

On the basis of the in vitro tests it was confirmed that it is possible to produce hydroxyapatite from bone waste from meat industry for medical applications. The tests proved that the calcining temperature had influence on calcium and phosphorus content in hydroxyapatite. On the grounds of the in vitro study it was stated that it is possible to use hydroxyapatite from bone waste as a material for bone implants and also in stomatology.

The analysed physiological fluids contained HAp samples that after sudden increase of $\mathrm{pH}$ showed a tendency to decrease with the immersion time. It concerned all the hydroxyapatite samples independently of the preparation temperature and applied fluid. A rapid growth of the $\mathrm{pH}$ value resulted from the free calcium oxide formation, which was incompletely removed from the samples after the preparation process. The highest $\mathrm{pH}$ value in comparison with pure physiological fluid for all the immersed time could result from the selective elution of calcium ions into the solutions. All the dense samples exhibit bioactivity properties.

The analyses of electric conductivity of distilled water showed in all the cases an increase in conductivity. The measurements confirmed that dense hydroxyapatite materials were characterised by a similar propensity to degradation.

\section{LITERATURE CITED}

1. Ślósarczyk, A., Stobierska, E. \& Paszkiewicz, Z. (1994). Hydroxyapatite as an implantological material Ceramics 46 Polish Ceramic Bulletin (in Polish).

2. Knychalska-Karwan, Z. \& Ślósarczyk, A. (1994). Hydroxyapatite in stomatology Krakmedia, Kraków (in Polish).

3. Ślósarczyk, A. (1997). Hydroxyapatite bioceramics Biuletyn Ceramiczny nr 13 Ceramika 51, Polskie Towarzystwo Ceramiczne, Kraków (in Polish).
4. Shin, H., Jo, S. \& Mikos, A.G. (2003). Biomimetic materials for tissue engineering. Biomaterials 24, 4353 - 4364.

5. Vallet-Regi, M. \& Gonzales-Calbert J. (2004). Calcium phosphates as substitution of bone tissues. Prog. Solid St. Chem. 32, 1 - 31. Received 1 December 2003; received in revised form 1 June 2004; accepted 15 July 2004, from Science Direct database on the World Wide Web: www.elsevier.nl/locate/pssc. j.progsolidstchem.2004.07.001.

6. Kokubo, T. \& Takadama, H. (2006). How useful is SBF in predicting in vivo bone bioactivity? Biomaterials 27, 2907 - 2915. Received 6 September 2005; accepted 13 January 2006 Available online 31 January 2006from Science Direct database on the World Wide Web: www.elsevier.com/locate/ biomaterials. DOI:10.1016/j.biomaterials.2006.01.017. 